\title{
Effects of celastrol on enhancing apoptosis of ovarian cancer cells via the downregulation of microRNA-21 and the suppression of the PI3K/Akt-NF-кB signaling pathway in an in vitro model of ovarian carcinoma
}

\author{
HAIYAN ZHANG ${ }^{1}$, JIANHUA LI ${ }^{2}$, GUANG LI $^{3}$ and SURONG WANG ${ }^{4}$ \\ ${ }^{1}$ Gynaecology Ward-1, Department of Gynaecology; Departments of ${ }^{2}$ Gynaecology Laboratory and ${ }^{3}$ Gastrointestinal Surgery; \\ ${ }^{4}$ Gynaecology Ward-3, Department of Gynaecology, Linyi People's Hospital, Linyi, Shandong 276003, P.R. China
}

Received March 13, 2015; Accepted May 22, 2016

DOI: $10.3892 / \mathrm{mmr} .2016 .5894$

\begin{abstract}
Celastrol has previously been used to treat rheumatoid arthritis, bruises, back pain and additional diseases. At present, efficacy studies predominantly focus on the anti-inflammatory, antioxidative and antitumor effects of celastrol. However, the effect of celastrol on ovarian cancer cells is not fully elucidated. In the present study, the effects of celastrol were investigated in ovarian cancer cells and the mechanisms involved were explored. In OVCAR3 cells, celastrol was observed to suppress cellular proliferation, induce apoptosis and increase caspase- 9 and -3 activity in a dose- and time-dependent manner. The expression levels of microRNA-21 (miRNA-21) were reduced, in addition to a reduction in the levels of phosphoinositide 3-kinase (PI3K)/p-Akt-NF $(\mathrm{NF})-\kappa \mathrm{B}$ following treatment with celastrol. Notably, reduced expression of miRNA-21 replicated the effect of celastrol on OVCAR 3 cells and inhibited the PI $3 \mathrm{~K} / \mathrm{p}-\mathrm{Akt}-\mathrm{NF}-\kappa \mathrm{B}$ signaling pathway in an in vitro model of ovarian carcinoma. To the best of our knowledge this is the first study to indicate that celastrol may represent a potential agent for the treatment of human ovarian carcinoma, via the induction of apoptosis through the downregulation of miRNA-21 and the PI3K/Akt-NF- $\kappa \mathrm{B}$ signaling pathway in an in vitro model of ovarian carcinoma.
\end{abstract}

\section{Introduction}

Ovarian carcinoma is a common female gynecological cancer, and its incidence ranks third to cervical cancer and endometrial cancer in China (1). However, due to the lack of obvious signs and symptoms in the early stages of ovarian carcinoma,

Correspondence to: Mr Jianhua Li, Department of Gynaecology Laboratory, Linyi People's Hospital, 27 Jiefang Road, Linyi, Shandong 276003, P.R. China

E-mail: lijianhuama@163.com

Key words: celastrol, ovarian carcinoma, phosphoinositide 3-kinase/Akt-nuclear factor- $\kappa \mathrm{B}$, miRNA-21 the majority of patients are diagnosed with ovarian cancer during the treatment of cancer in other organs (2). Therefore, ovarian carcinoma is commonly identified only at advanced stages, resulting in the greatest mortality rate of all types of gynecological cancer and representing a serious threat to female health (3).

MicroRNAs (miRNAs) are non-coding single-stranded small RNA molecules, which are highly conserved and exist in animals and plants. miRNAs consist of a single-chain 21-25 nt in length (4). miRNAs are produced by gene transcription, following which miRNAs bind to their target gene and regulate its expression. miRNA-21 has been observed to be associated with tumor occurrence and development in numerous types of cancer, including liver, non-small cell lung, stomach, breast, and esophageal cancer, and tumors of the nervous system $(5,6)$.

Numerous previous studies have indicated that the phosphoinositide 3-kinase (PI3K)/AKT signaling pathway serves an important role in the proliferation, angiogenesis and metastasis of ovarian carcinoma, and the tumor resistance to radiotherapy and chemotherapy $(7,8)$. The PI3K/Akt-nuclear factor- $\kappa \mathrm{B}(\mathrm{NF}-\kappa \mathrm{B})$ signaling pathway stimulates an increase in the expression levels of vascular endothelial growth factor (VEGF) to promote angiogenesis in ovarian carcinoma (9).

Celastrol is a herb found in numerous regions of China, with extensive pharmacological effects (10). Celastrol is a pentacyclic triterpene monomer extracted from the root of Tripterygium wilfordii. In an in vitro study, celastrol was indicated to exert inhibitory effects on angiogenesis in vascular endothelial cells and on the proliferation of endothelial cells (11). In the present study, the effects of celastrol were investigated in OVCAR3 cells and the anticancer mechanisms of celastrol were explored.

\section{Materials and methods}

Materials. Dulbecco's modified Eagle's medium (DMEM) and fetal bovine serum (FBS) were purchased from Gibco, Thermo Fisher Scientific (Waltham, MA, USA). 3-(4,5-Dimethylthiazol-2-yl)-2,5-diphenyltetrazolium bromide (MTT) and celastrol (Fig. 1) were purchased from Sigma-Aldrich (St. Louis, MO, USA). The 
Annexin V/propidium iodide (PI) staining kit was purchased from BD Biosciences (San Jose, CA, USA). The bicinchoninic acid (BCA) protein assay kit was purchased from Santa Cruz Biotechnology, Inc. (Dallas, TX, USA).

Cell culture. OVCAR3 human ovarian carcinoma cells were purchased from the Shanghai Cell Bank of the Chinese Academy of Sciences (Shanghai, China) and cultivated in DMEM with $10 \% \mathrm{FBS}, 100 \mathrm{U} / \mathrm{ml}$ penicillin and $100 \mu \mathrm{g} / \mathrm{ml}$ streptomycin (Sangon Biotech Co., Ltd., Shanghai, China) at $37^{\circ} \mathrm{C}$ in a $5 \% \mathrm{CO}_{2}$ incubator.

MTT assay. OVCAR3 cells (4,000 cells/well) were seeded and cultured in 96-well microplates overnight. Subsequently, OVCAR3 cells were treated with varying concentrations of celastrol $(0,0.25,0.5,1,2,4$ and $6 \mu \mathrm{M})$ for $0,1,2$ and 3 days. A total of $10 \mu \mathrm{l}$ MTT $(5 \mathrm{mg} / \mathrm{ml})$ solution was added to each well and incubated at a temperature of $37^{\circ} \mathrm{C}$ in a humidified atmosphere of $5 \% \mathrm{CO}_{2}$. Following this, $100 \mu \mathrm{l}$ of the resolving solution [10\% sodium dodecyl sulfate (SDS) and $0.1 \mathrm{mM} \mathrm{HCl}]$ was added to each well and incubated for $10 \mathrm{~min}$ at room temperature whilst the plate was agitated. The absorbance of the plate was measured at $570 \mathrm{~nm}$ using the Multiskan EX Primary EIA V.2.1-1 spectrophotometer.

Apoptosis levels using Annexin V/PI staining. Following treatment with celastrol $(1,2$ and $4 \mu \mathrm{M})$ for 2 days, OVCAR3 cells were harvested and washed with phosphate-buffered saline. OVCAR3 cells were re-suspended with $1 \mathrm{X}$ binding buffer prior to staining with Annexin V for $30 \mathrm{~min}$ at room temperature in the dark. OVCAR3 cells were then double-stained with PI for $30 \mathrm{~min}$ at room temperature in the dark. The apoptotic OVCAR3 cells were quantitatively counted by a flow cytometer.

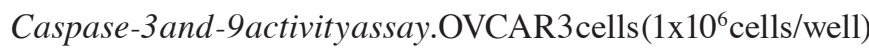
were seeded and cultured in 6-well microplates overnight at $37^{\circ} \mathrm{C}$ in a $5 \% \mathrm{CO}_{2}$ incubator. Subsequently, the OVCAR3 cells were treated with varying concentrations of celastrol (1, 2 and $4 \mu \mathrm{M}$ ) for 2 days. Following treatment with celastrol, the OVCAR3 cells were prepared in cell lysis buffer (Beyotime Institute of Biotechnology, Haimen, China) for 30-60 min and centrifuged at $12,000 \mathrm{x} g$ for $10 \mathrm{~min}$ at $4^{\circ} \mathrm{C}$. The protein concentration was measured using a BCA protein assay kit. An equal quantity of total protein extract was mixed with the reaction buffer (acetyl-Leu-Glu-His-Asp-p-nitroanilide for caspase-9 and acetyl-Asp-Glu-Val-Asp-p-nitroanilide for caspase-3) (Beyotime Institute of Biotechnology) for 4-6 h. Caspase-9 and -3 activity was measured at an absorbance of $405 \mathrm{~nm}$.

Quantitative polymerase chain reaction ( $q P C R)$ analysis of miRNA-21 expression. OVCAR3 cells ( $1 \times 10^{6}$ cells/well) were seeded and cultured in 6-well microplates overnight at $37^{\circ} \mathrm{C}$. Subsequently, OVCAR 3 cells were treated with varying concentrations of celastrol $(1,2$ and $4 \mu \mathrm{M})$ for 2 days. Following treatment with celastrol, OVCAR3 cells were prepared in cell lysis buffer for 30-60 min and centrifuged at 12,000 x $\mathrm{g}$ for $10 \mathrm{~min}$ at $4^{\circ} \mathrm{C}$. Total RNA was extracted from the cell lysate using TRIzol reagent (Invitrogen; Thermo Fisher Scientific, Inc.). Total RNA (1-2 $\mu \mathrm{g})$ was reversed transcribed into to cDNA using PrimeScript RT Master Mix (Takara Bio, Inc.,
Otsu, Japan). qPCR was conducted using the ABI 7500 system (Takara Bio, Inc.). The cycling conditions were as follows: One cycle at $94^{\circ} \mathrm{C}$ for $5 \mathrm{~min}$, followed by 30 cycles at $95^{\circ} \mathrm{C}$ for $15 \mathrm{sec}, 60^{\circ} \mathrm{C}$ for $30 \mathrm{sec}$ and $72^{\circ} \mathrm{C}$ for $30 \mathrm{sec}$. The relative expression of miRNA-21 was measured using a Bulge-Loop miRNA qRT-PCR kit (Invitrogen; Thermo Fisher Scientific, Inc.). The primers used were as follow: miRNA-21, forward 5'-GCC CGCTAGCTTATCAGACTGATG-3' and reverse 5'-GCC CGCTAGCTTATCAGACTGATG-3'; and U6 forward 5'-GTT GACATCCGTAAAGACC-3' and reverse 5'-GGAGCCAGG GCAGTAA-3'.

Western blot analysis. OVCAR3 cells $\left(1 \times 10^{6}\right.$ cells/well) were seeded and cultured in 6-well microplates overnight at $37^{\circ} \mathrm{C}$ in a $5 \% \mathrm{CO}_{2}$ incubator. Subsequently, OVCAR3 cells were treated with varying concentrations of celastrol $(1,2$ and $4 \mu \mathrm{M})$ for 2 days. Following treatment with celastrol, the OVCAR3 cells were prepared in radioimmunoprecipitation assay lysis buffer with protease and phosphatase inhibitors (Beyotime Institute of Biotechnology) for 30-60 min and centrifuged at 12,000 $\mathrm{x} g$ for $10 \mathrm{~min}$ at $4^{\circ} \mathrm{C}$. The protein concentration was measured using a BCA protein assay kit. A total of $30 \mu \mathrm{g}$ of total protein lysate was loaded and electrophoresed onto $10 \%$ SDS-polyacrylamide gels (Sangon Biotech Co., Ltd.) and the separated proteins were transferred to polyvinylidene fluoride membranes (EMD Millipore, Billerica, MA, USA). The membranes were blocked with $5 \%$ fat-free milk in Tris-buffered saline with $0.1 \%$ Tween-20 (TBST) for $2 \mathrm{~h}$ at room temperature. The membranes were then incubated with anti-PI3K (sc-67306; 1:500; Santa Cruz Biotechnology, Inc.), anti-phosphorylated-Akt (p-Akt; sc-7985-R and sc-1618; 1:1,000; Santa Cruz Biotechnology, Inc.), anti-NF-кB (sc-109; 1:1,000; Santa Cruz Biotechnology, Inc.) and anti- $\beta$-actin (sc-130657; 1:500; Santa Cruz Biotechnology, Inc.) overnight at $4^{\circ} \mathrm{C}$. Following washing with TBST three times for $2 \mathrm{~h}$ at room temperature, secondary fluorescent antibodies were incubated with the membranes at room temperature for $2 \mathrm{~h}$. Proteins were visualized using an LI-COR Odyssey scanner (LI-COR, Inc., Lincoln, NE, USA).

Transfection plasmid. Anti-miRNA-21 plasmids were chemically synthesized by BeastBio Co., Ltd. (Shanghai, China). OVCAR3 cells $\left(1 \times 10^{6}\right.$ cells/well) were seeded and cultured in 6-well microplates overnight. A total of $100 \mathrm{pmol} / 1$ anti-miRNA-21 plasmid was transfected into the OVCAR3 cells with Lipofectamine 2000 serum medium (Invitrogen; Thermo Fisher Scientific) for $24 \mathrm{~h}$. Subsequently, the transfected OVCAR3 cells were treated with celastrol for $48 \mathrm{~h}$.

Statistical analysis. Statistical analysis was conducted with SPSS software, version 18.0 (SPSS, Inc., Chicago, IL, USA). Values are presented as the mean \pm standard error. Experiments were conducted a minimum of three times. Differences between the groups were assessed by two-way analysis of variance and no post hoc tests were used. $\mathrm{P}<0.01$ was considered to indicate a statistically significant difference.

\section{Results}

Effects of celastrol on the cellular proliferation of ovarian carcinoma cells. The effects of celastrol on the cellular prolif- 


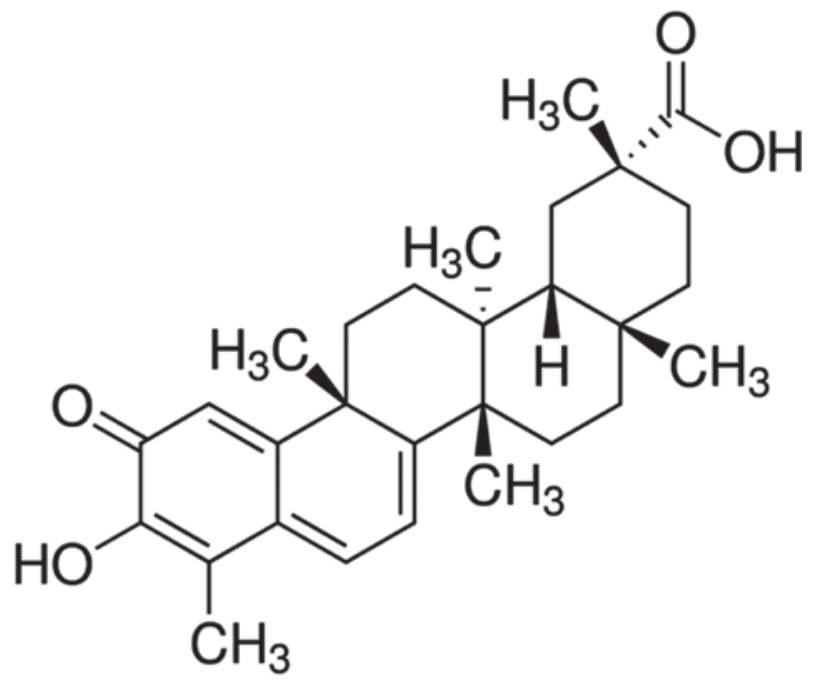

Figure 1. Chemical structure of celastrol.

eration of ovarian carcinoma cells was investigated using an MTT assay. OVCAR3 cells were treated with a range of celastrol concentrations $(0,0.25,0.5,1,2,4$ and $6 \mu \mathrm{M})$ for 0 , 1, 2 and 3 days. As presented in Fig. 2, the proliferation of OVCAR3 cells was inhibited following treatment with celastrol in a dose- and time-dependent manner. Treatment with celastrol $(1,2,4$ and $6 \mu \mathrm{M})$ for 3 days or celastrol $(2,4$ and $6 \mu \mathrm{M})$ for 2 days resulted in significant reductions in cellular proliferation $(\mathrm{P}<0.01$; Fig. 2). These results suggest that celastrol exerted clear anticancer effects on human ovarian carcinoma cells.

Effects of celastrol on apoptosis in ovarian carcinoma cells. The effects of celastrol on apoptosis in ovarian carcinoma cells was investigated using Annexin V/PI staining. As presented in Fig. 3, celastrol induced apoptosis in ovarian carcinoma cells in a dose-dependent manner, with a significant increase in the levels of apoptotic cells following celastrol treatment for 2 days at 2 and $4 \mu \mathrm{M}(\mathrm{P}<0.01$; Fig. 3$)$.

Effects of celastrol on caspase-9 and -3 activity in ovarian carcinoma cells. To further investigate the effects of celastrol treatment on apoptosis in ovarian carcinoma cells, the activity levels of caspase-9 and -3 was investigated. As presented in Fig. 4, celastrol increased the activity levels of caspase-9 and -3 in ovarian carcinoma cells in a dose-dependent manner. Treatment with celastrol ( 2 and $4 \mu \mathrm{M})$ for 2 days resulted in a significant increase in the activity levels of caspase-9 and $-3(\mathrm{P}<0.01$; Fig. 4).

Effects of celastrol on miRNA-21 expression in ovarian carcinoma cells. To explore the mechanisms involved in the effect of celastrol on ovarian carcinoma cells, miRNA-21 expression was measured using qPCR. The relative expression levels of miRNA-21 in OVCAR3 cells was reduced following treatment with celastrol ( 2 and $4 \mu \mathrm{M})$ for 2 day $(\mathrm{P}<0.01$; Fig. 5). These results indicated that the anticancer effect of celastrol may be involved with reducing miRNA-21 levels.

Effects of celastrol on the expression levels of PI3K/Akt in ovarian carcinoma cells. To investigate the mechanisms involved in the effect of celastrol treatment on ovarian carcinoma cells, the expression levels of PI3K/Akt were measured in ovarian carcinoma cells using western blot analysis. Following treatment with celastrol ( 2 and $4 \mu \mathrm{M}$ ) for 2 days, the protein expression levels of PI3K and p-Akt were reduced in OVCAR3 cells $(\mathrm{P}<0.01$; Fig. 6). These results indicate that the anticancer effects of celastrol may be associated with the suppression of the PI3K/Akt signaling pathway.

Effects of celastrol on $N F-\kappa B$ protein expression in ovarian carcinoma cell. To further investigate the mechanisms involved in the effect of celastrol treatment on ovarian carcinoma cells, NF- $\kappa \mathrm{B}$ protein expression was measured by western blot analysis. Following treatment with celastrol ( 2 and $4 \mu \mathrm{M}$ ) for 2 days, the expression levels of $\mathrm{NF}-\kappa \mathrm{B}$ in OVCAR3 cells were significantly reduced $(\mathrm{P}<0.01$; Fig. 7 ). These results indicated that the anticancer effect of celastrol may be associated with the suppression of the $\mathrm{NF}-\kappa \mathrm{B}$ signaling pathway.

Effect of downregulation of miRNA-21 on PI3K/Akt/NF- $\mathrm{BB}$ expression. To further analyze the mechanisms involved in the effect of celastrol treatment on ovarian carcinoma cells, anti-miRNA-21 plasmids were transfected into OVCAR3 cells. As presented in Fig. 8A, the anti-miRNA-21 plasmids significantly reduced the relative expression levels of miRNA-21 in OVCAR3 cells. In addition, the anti-miRNA-21 plasmids were able to reduce the cellular proliferation of OVCAR3 cells (Fig. 8B). Notably, the anti-miRNA-21 plasmids suppressed the PI3K/Akt-NF- $\kappa \mathrm{B}$ signaling pathway in ovarian carcinoma cells (Fig. 8C-F).

\section{Discussion}

Ovarian carcinoma is the most common ovarian cancer, and has the greatest associated mortality of all types of female gynecological cancer (12). Despite the progress made in the treatments available for ovarian carcinoma, the prognosis remains poor, with a mortality rate of 22/100,000 and a 5-year survival rate of 25-30\% (13). Therefore, ovarian carcinoma is an important disease in the field of gynecology, of which the etiology, pathogenesis, biological characteristics and exploration of novel effective treatments are the focus of research (14). To the best of our knowledge, the current study is the first to demonstrate that celastrol is an effective and potent agent in treating ovarian carcinoma cells in vitro. Celastrol exerted anticancer effects on ovarian carcinoma cells via a reduction in the cellular proliferation and the activation of caspase-dependent apoptosis in OVCAR3 cells. Previous reports have indicted that celastrol significantly inhibits the cellular proliferation and induces apoptosis in gastric cancer cells $(15,16)$ and prostate cancer cells $(17)$.

miRNA are a type of non-coding single-stranded small RNA molecules, which are highly conserved and exist widely in animals and plants. Previous studies have indicated that there are significant differences in the expression profile of miRNA between cancer cells and normal tissues $(18,19)$. The alterations in the expression of miRNA are associated with tumorigenesis, and the treatment and prognosis of cancer (20). A previous study indicated that the expression levels of 


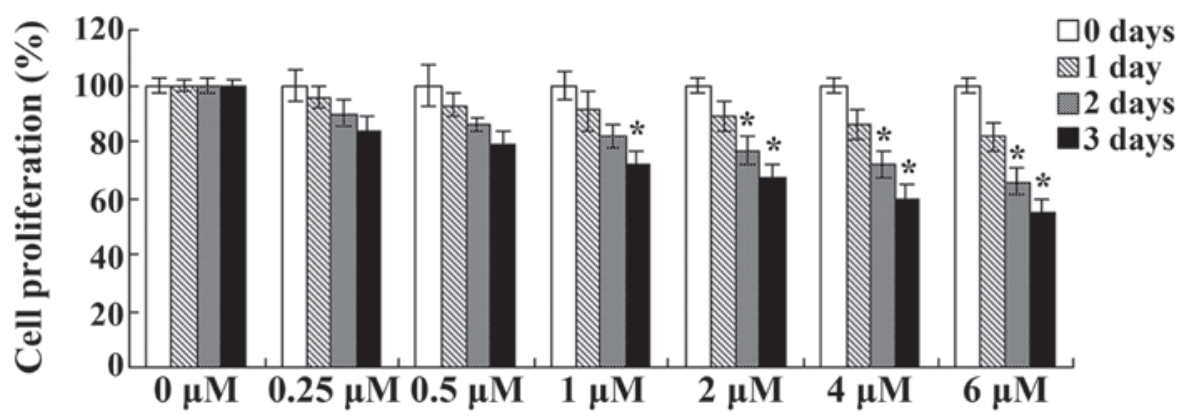

Figure 2. Effect of celastrol on the proliferation of ovarian carcinoma cells. ${ }^{*} \mathrm{P}<0.01$ vs. the $0 \mu \mathrm{M}$ group.

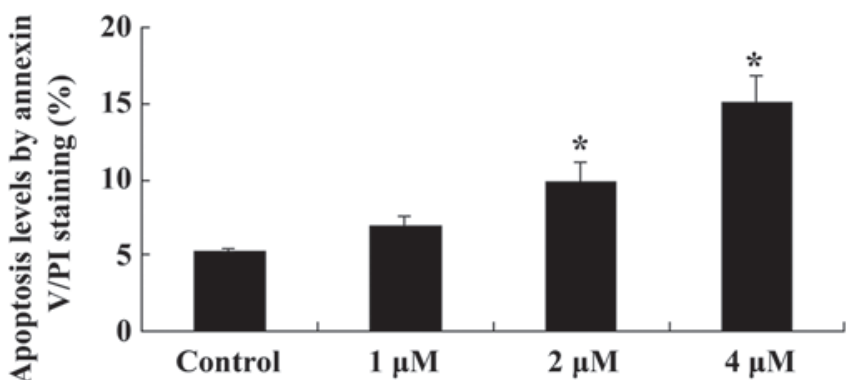

Figure 3. Effect of celastrol on apoptosis in ovarian carcinoma cells. ${ }^{*} \mathrm{P}<0.01$ vs. the control group. PI, propidium iodide.
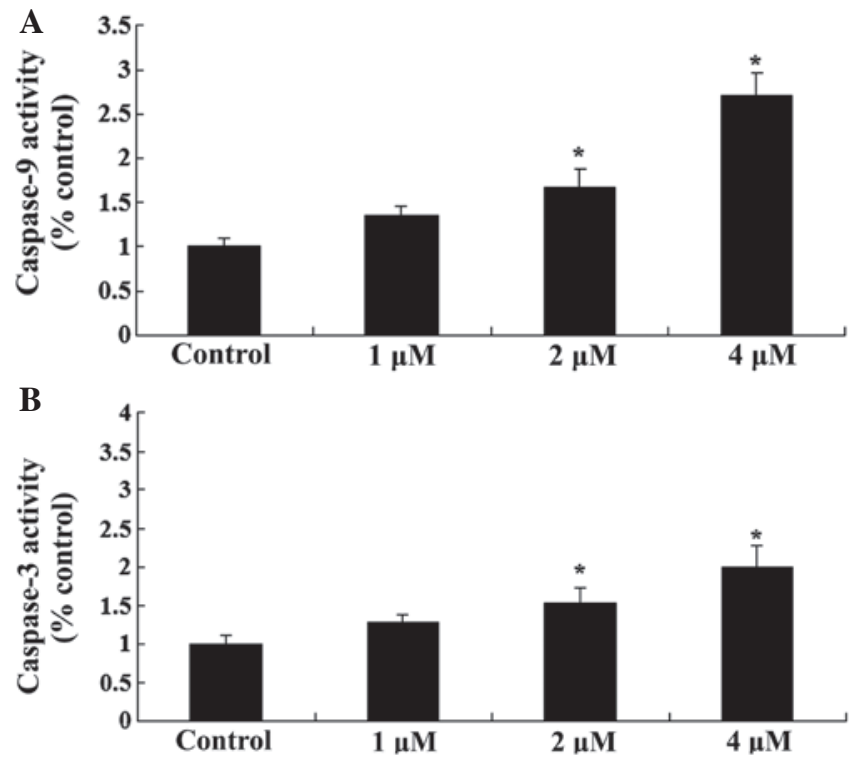

Figure 4. Effect of celastrol on (A) caspase-9 and (B) caspase-3 activity in ovarian carcinoma cells. ${ }^{*} \mathrm{P}<0.01$ vs. the control group.

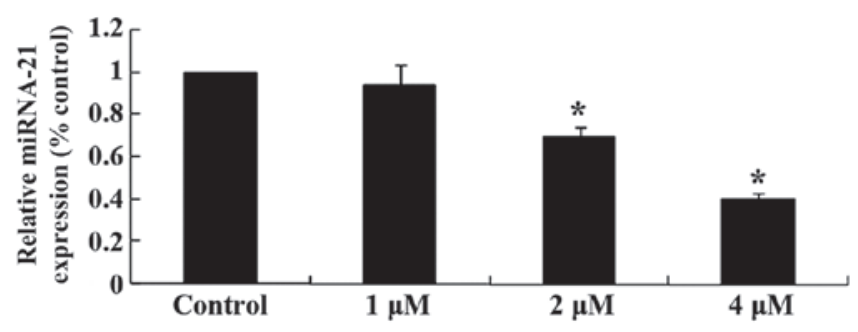

Figure 5. Effect of celastrol on miRNA-21 expression levels in ovarian carcinoma cells. "P<0.01 vs. the control group. miRNA-21, microRNA-21.

\section{A PI3K p-Akt Akt \\ $\beta$-actin}

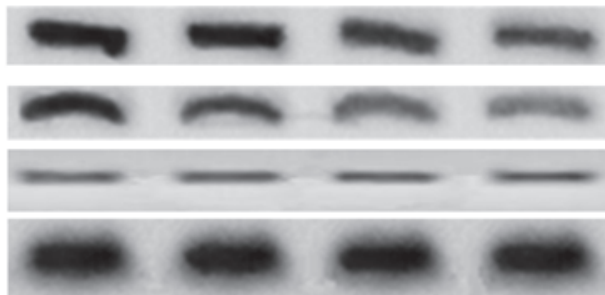

Control $1 \mu \mathrm{M} \quad 2 \mu \mathrm{M} \quad 4 \mu \mathrm{M}$

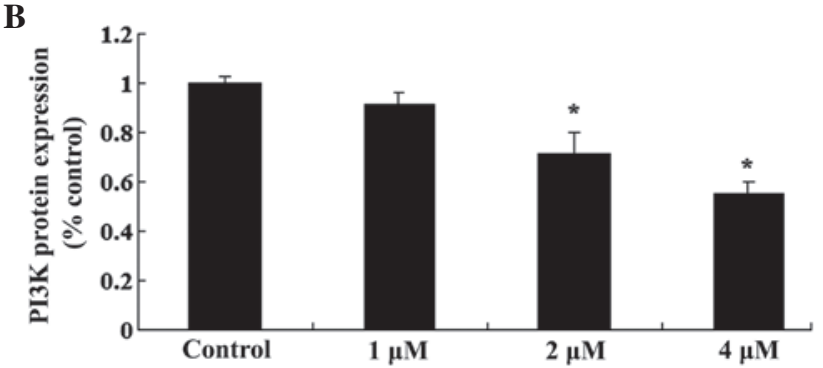

C

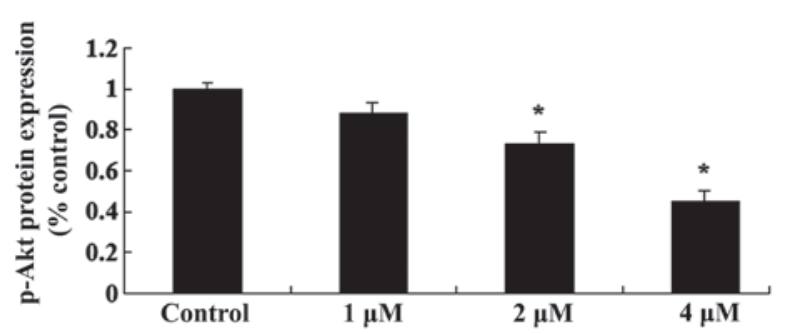

Figure 6. Effect of celastrol on PI3K/Akt protein expression levels in ovarian carcinoma cells. (A) Western blot images and the quantification of the expression levels of (B) PI3K and (C) p-Akt. "P<0.01 vs. the control group. PI3K, phosphoinositide 3-kinase; p-, phosphorylated.

miRNA-21 were increased in the tissues of breast, stomach, liver and cervical cancer, indicating that miRNA-21 may serve a role as an oncogene in tumorigenesis (21). However, reports of miRNA-21 expression in ovarian carcinoma tissue are inconsistent, though the majority indicate upregulated expression (22). In a previous study, microarrays and additional methods were used to screen miRNA expression in ovarian carcinoma tissue, and demonstrated that 12 miRNAs were upregulated, including miRNA-21 (23). The current study demonstrated that treatment with celastrol inhibited the relative expression levels of miRNA-21 in OVCAR3 cells. Sha et al (16) reported that celastrol induced apoptosis in gastric cancer cells via the miRNA-21-mediated inhibition of the PI3K/Akt-NF- $\mathrm{KB}$ signaling pathway. 


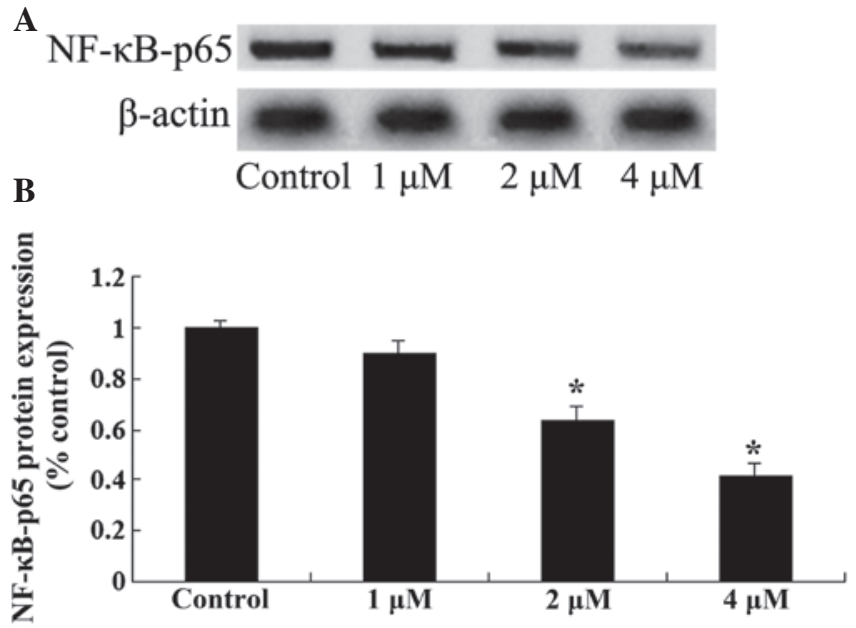

Figure 7. Effect of celastrol on the expression levels of NF- $\mathrm{\kappa B}$ in ovarian carcinoma cells. (A) Western blot images and (B) the quantification of the expression levels of NF- $\kappa B$. ${ }^{*} \mathrm{P}<0.01$ vs. the control group. NF- $\kappa \mathrm{B}$, nuclear factor- $\mathrm{\kappa} \mathrm{B}$.

$\mathrm{PI} 3 \mathrm{~K}$ is a member of the lipid kinase family and is involved in the regulation of cellular metabolism, survival and proliferation. Akt is an important protein kinase downstream of $\mathrm{PI} 3 \mathrm{~K}$, and its continuous activation is closely associated with tumor development $(24,25)$. In breast and ovarian cancer, as well as additional malignancies, the PI3K/Akt pathway has been observed to be resistant to the induction of apoptosis by chemotherapy and radiotherapy $(26,27)$. Selective inhibition of PI3K or Akt activity reduces the phosphorylation levels of Akt, which is able to increase the sensitivity of the cells to the induction of apoptosis by chemotherapy and radiotherapy (28). The current study indicates that celastrol treatment reduced the protein expression levels of PI3K and p-Akt in OVCAR3 cells. In a previous study, Lee et al (29) indicated that treatment with celastrol was able to suppress cell growth and increase apoptosis in melanoma cells through the suppression of PI3K/AKT signaling. Sha et al (16) demonstrated that celastrol induces apoptosis in gastric cancer cells via the inhibition of the PI3K/Akt-NF-кB signaling pathway by miRNA-21.

The PI3K/Akt pathway directly or indirectly affects downstream processes that are associated with cellular proliferation, protein synthesis and certain apoptosis-associated factors. $\mathrm{NF}-\kappa \mathrm{B}$ is a key factor downstream of Akt, and under physiological conditions is bound to its inhibitor, I $\mathrm{B}$, and is localized in the cytoplasm in an inactive form (30). The activation of $\mathrm{NF}-\kappa \mathrm{B}$ results in the regulation of gene transcription associated with the promotion of cellular proliferation and the inhibition of apoptosis (31). The present study indicated that treatment with celastrol reduced the expression levels of $N F-\kappa B$ in OVCAR3 cells. Youn et al (32) reported that celastrol treatment ameliorated human immunodeficiency virus-1 Tat-induced inflammatory responses via the inhibition of NF- $\mathrm{KB}$ (32).

The current study demonstrated that the downregulation of miRNA-21 expression was able to replicate the anticancer effect of celastrol on OVCAR3 cells, resulting in a reduction in the expression levels of PI3K/Akt-NF- $\kappa \mathrm{B}$ in OVCAR3 cells. In conclusion, the current study indicates that celastrol is able to significantly suppress cellular proliferation and induce
A

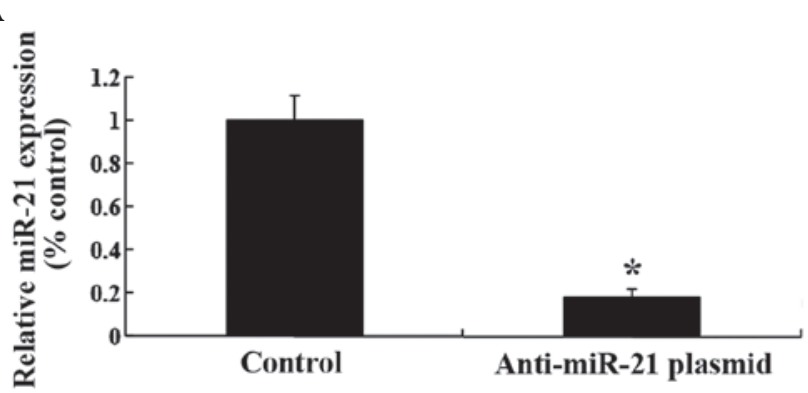

B

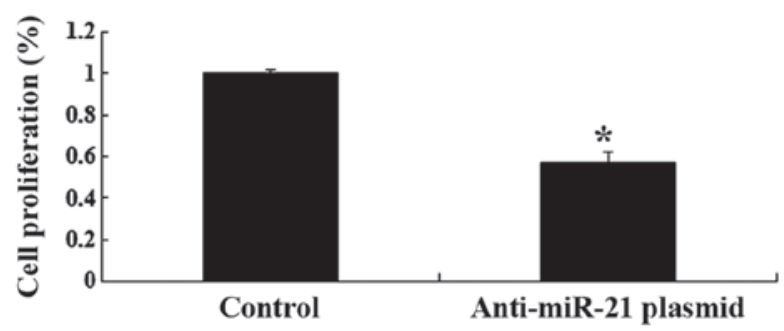

C

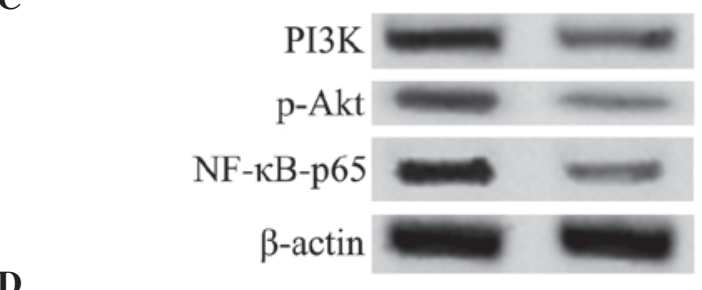

D

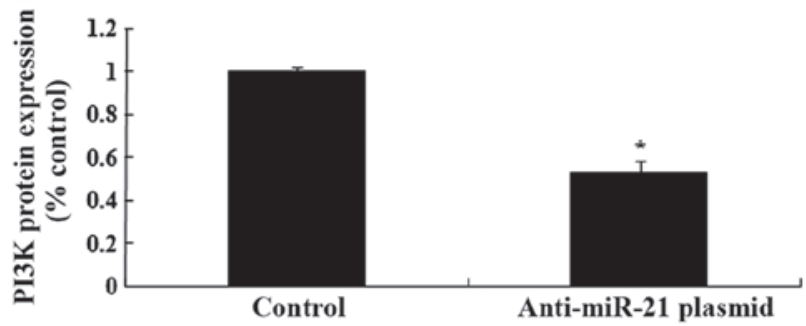

E

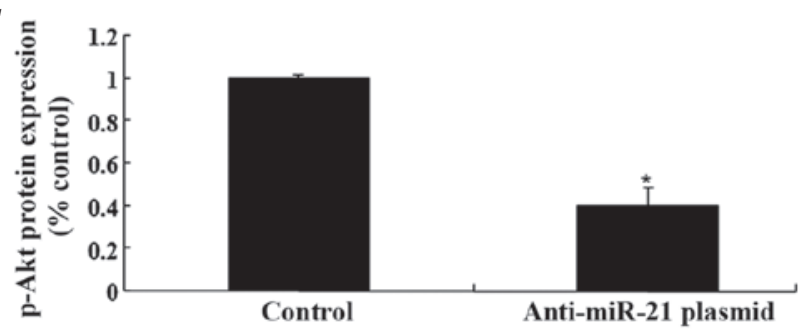

F

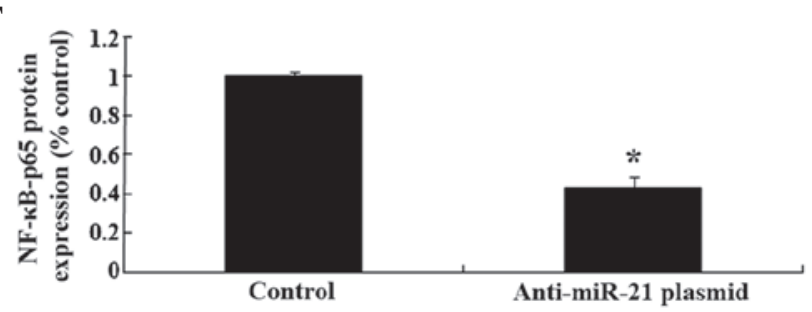

Figure 8. Effect of downregulation of miRNA-21 on the expression levels of PI3K/Akt/NF-kB in ovarian carcinoma cells. (A) The expression levels of miRNA-21 are reduced by the miRNA-21 plasmid. (B) The effect of the miRNA-21 plasmid on cellular proliferation in ovarian carcinoma cells. (C) Western blot images of the protein expression of PI3K, p-Akt and NF- $\mathrm{KB}$, and the quantification of (D) PI3K, (E) p-Akt and (F) NF- $\mathrm{kB}$ protein expression levels. "P<0.01 vs. the control group. miRNA-21, microRNA-21; PI3K, phosphoinositide 3-kinase; p-Akt, phosphorylated protein kinase B; NF-кB, nuclear factor- $\mathrm{\kappa} \mathrm{B}$. 
apoptosis of OVCAR3 cells. These results demonstrated that celastrol may represent a potential novel anticancer treatment, with its mechanisms associated with the downregulation of microRNA-21 and the suppression the PI3K/Akt-NF- $\mathrm{KB}$ signaling pathway in an in vitro model of ovarian carcinoma.

\section{References}

1. Ren Y, Huang X, Shan B, Wu X, Huang X, Shi D and Wang H: Adjuvant concurrent chemoradiation followed by chemotherapy for high-risk endometrial cancer. Gynecol Oncol 140: 58-63, 2016.

2. Bao LJ, Jaramillo MC, Zhang ZB, Zheng YX, Yao M, Zhang DD and Yi XF: Nrf2 induces cisplatin resistance through activation of autophagy in ovarian carcinoma. Int J Clin Exp Pathol 7: $1502-1513,2014$

3. Krtolica A, Krucher NA and Ludlow JW: Molecular analysis of selected cell cycle regulatory proteins during aerobic and hypoxic maintenance of human ovarian carcinoma cells. Br J Cancer 80: 1875-1883, 1999.

4. Li X, Abdel-Mageed AB, Mondal D and Kandil E: MicroRNA expression profiles in differentiated thyroid cancer, a review. Int J Clin Exp Med 6: 74-80, 2013.

5. Kumarswamy R, Volkmann I and Thum T: Regulation and function of miRNA-21 in health and disease. RNA Biol 8: 706-713, 2011.

6. Bonci D: MicroRNA-21 as therapeutic target in cancer and cardiovascular disease. Recent Patents Cardiovasc Drug Discov 5: 156-161, 2010.

7. Liu J, Lin B, Hao Y, Qi Y, Zhu L, Li F, Liu D, Cong J, Zhang S and Iwamori M: Lewis y antigen promotes the proliferation of ovarian carcinoma-derived RMG-I cells through the PI3K/Akt signaling pathway. J Exp Clin Cancer Res 28: 154, 2009.

8. Zi D, Zhou ZW, Yang YJ, Huang L, Zhou ZL, He SM, He ZX and Zhou SF: Danusertib induces apoptosis, cell cycle arrest, and autophagy but inhibits epithelial to mesenchymal transition involving PI $3 \mathrm{k} / \mathrm{Akt} / \mathrm{mTOR}$ signaling pathway in human ovarian cancer cells. Int J Mol Sci 16: 27228-27251, 2015.

9. Chou CH, Wei LH, Kuo ML, Huang YJ, Lai KP, Chen CA and Hsieh CY: Up-regulation of interleukin-6 in human ovarian cancer cell via a Gi/PI3K-Akt/NF-kappaB pathway by lysophosphatidic acid, an ovarian cancer-activating factor. Carcinogenesis 26: 45-52, 2005

10. Astry B, Venkatesha SH, Laurence A, Christensen-Quick A, Garzino-Demo A, Frieman MB, O'Shea JJ and Moudgil KD: Celastrol, a Chinese herbal compound, controls autoimmune inflammation by altering the balance of pathogenic and regulatory $\mathrm{T}$ cells in the target organ. Clin Immunol 157: 228-238, 2015.

11. Kannaiyan R, Shanmugam MK and Sethi G: Molecular targets of celastrol derived from Thunder of God Vine: Potential role in the treatment of inflammatory disorders and cancer. Cancer Lett 303: 9-20, 2011.

12. Luo C, Shibata K, Suzuki S, Kajiyama H, Senga T, Koya Y, Daimon M, Yamashita M and Kikkawa F: GPC3 expression in mouse ovarian cancer induces GPC3-specific T cell-mediated immune response through M1 macrophages and suppresses tumor growth. Oncol Rep 32: 913-921, 2014.

13. Nakanishi T, Aoki D, Watanabe Y, Ando Y, Tomotsugu N, Sato Y and Saito T: A Phase II clinical trial of pegylated liposomal doxorubicin and carboplatin in Japanese patients with platinum-sensitive recurrent ovarian, fallopian tube or primary peritoneal cancer. Jpn J Clin Oncol 45: 422-426, 2015.

14. Fruscio R, Colombo N, Lissoni AA, Garbi A, Fossati R, Ieda' N, Torri $\mathrm{V}$ and Mangioni C: A phase II randomised clinical trial comparing cisplatin, paclitaxel and ifosfamide with cisplatin, paclitaxel and epirubicin in newly diagnosed advanced epithelial ovarian cancer: Long-term survival analysis. Br J Cancer 98 720-727, 2008
15. Lee HW, Jang KS, Choi HJ, Jo A, Cheong JH and Chun KH: Celastrol inhibits gastric cancer growth by induction of apoptosis and autophagy. BMB Rep 47: 697-702, 2014.

16. Sha M, Ye J, Zhang LX, Luan ZY, Chen YB and Huang JX: Celastrol induces apoptosis of gastric cancer cells by miR-21 inhibiting PI3K/Akt-NF- $\mathrm{BB}$ signaling pathway. Pharmacology 93 39-46, 2014.

17. Wolfram J, Suri K, Huang Y, Molinaro R, Borsoi C, Scott B, Boom K, Paolino D, Fresta M, Wang J, et al: Evaluation of anticancer activity of celastrol liposomes in prostate cancer cells. J Microencapsul 31: 501-507, 2014.

18. Kiga K, Fukuda-Yuzawa Y, Tanabe M, Tsuji S, Sasakawa C and Fukao T: Comprehensive silencing of target-sharing microRNAs is a mechanism for SIRT1 overexpression in cancer. RNA Biol 11: 1347-1354, 2014.

19. Mezzanzanica D, Canevari S, Cecco LD and Bagnoli M: miRNA control of apoptotic programs: Focus on ovarian cancer. Expert Rev Mol Diagn 11: 277-286, 2011.

20. Wang J, Yu H, Ye L, Jin L, Yu M and Lv Y: Integrated regulatory mechanisms of miRNAs and targeted genes involved in colorectal cancer. Int J Clin Exp Pathol 8: 517-529, 2015.

21. Huang Y, Yang YB, Zhang XH, Yu XL, Wang ZB and Cheng XC: MicroRNA-21 gene and cancer. Med Oncol 30: 376, 2013.

22. Vaksman O, Tropé C, Davidson B and Reich R: Exosome-derived miRNAs and ovarian carcinoma progression. Carcinogenesis 35: 2113-2120, 2014

23. Echevarría-Vargas IM, Valiyeva F and Vivas-Mejía PE: Upregulation of miR-21 in cisplatin resistant ovarian cancer via JNK-1/c-Jun pathway. PLoS One 9: e97094, 2014.

24. Bommareddy A, Crisamore K, Fillman S, Brozena S, Steigerwalt J, Landis T, Vanwert AL and Dwivedi C: Survivin down-regulation by $\alpha$-santalol is not mediated through PI3K-AKT pathway in human breast cancer cells. Anticancer Res 35: 5353-5357, 2015.

25. Hussain A, Qazi AK, Mupparapu N, Kumar A, Mintoo MJ, Mahajan G, Sharma PR, Singh SK, Bharate SB, Zargar MA, et al: A novel PI3K axis selective molecule exhibits potent tumor inhibition in colorectal carcinogenesis. Mol Carcinog: Jan 13, 2016 (Epub ahead of print).

26. Wang JH, Nao JF, Zhang M and He P: 20(s)-ginsenoside Rg3 promotes apoptosis in human ovarian cancer HO-8910 cells through PI3K/Akt and XIAP pathways. Tumour Biol 35: 11985-11994, 2014.

27. Chang $\mathrm{CH}$, Ou TT, Yang MY, Huang $\mathrm{CC}$ and Wang CJ: Nelumbo nucifera Gaertn leaves extract inhibits the angiogenesis and metastasis of breast cancer cells by downregulation connective tissue growth factor (CTGF) mediated PI3K/AKT/ERK signaling. J Ethnopharmacol: May 10, 2016 (Epub ahead of print).

28. Ye Y, Tang X, Sun Z and Chen S: Upregulated WDR26 serves as a scaffold to coordinate PI3K/ AKT pathway-driven breast cancer cell growth, migration, and invasion. Oncotarget: Feb 17, 2016 (Epub ahead of print).

29. Lee JH, Won YS, Park KH, Lee MK, Tachibana H, Yamada K and Seo KI: Celastrol inhibits growth and induces apoptotic cell death in melanoma cells via the activation ROS-dependent mitochondrial pathway and the suppression of PI3K/AKT signaling. Apoptosis 17: 1275-1286, 2012.

30. Bai L, Xu S, Chen W, Li Z, Wang X, Tang H and Lin Y: Blocking NF- $\kappa$ B and Akt by Hsp90 inhibition sensitizes Smac mimetic compound 3-induced extrinsic apoptosis pathway and results in synergistic cancer cell death. Apoptosis 16: 45-54, 2011.

31. Liu T, Liu D, Liu J, Song JT, Gao SL, Li H, Hu LH and Liu BR: Effect of NF- $\kappa \mathrm{B}$ inhibitors on the chemotherapy-induced apoptosis of the colon cancer cell line HT-29. Exp Ther Med 4: 716-722, 2012.

32. Youn GS, Kwon DJ, Ju SM, Rhim H, Bae YS, Choi SY and Park J: Celastrol ameliorates HIV-1 Tat-induced inflammatory responses via NF-kappaB and AP-1 inhibition and heme oxygenase-1 induction in astrocytes. Toxicol Appl Pharmacol 280: 42-52, 2014. 